\title{
Workloads in genitourinary medicine clinics in England
}

\author{
R N T THIN* \\ From the Department of Genitourinary Medicine, St Thomas' Hospital, London, UK
}

SUMMARY Work loads in venereal disease-sexually transmitted disease (STD)-genitourinary medicine (GUM) clinics have risen greatly in recent years. The increase in viral infections which are more difficult and time consuming to manage than those caused by bacteria and the higher expectations and demands of patients have combined to increase workloads more than the case figures indicate. This prompted the Department of Health and Social Security in 1988 to set up a survey of clinics.in England with the following terms of reference:

"To examine current and forecast workloads on GUM clinics, taking account of AIDS and other STDs, and to recommend any action which may need to be taken on manpower (including nursing manpower), training, resources and accommodation".

The team concluded that the GUM service was ill equipped to meet the demands for its services, and made 36 recommendations. The priority recommendations included: the need to provide more resources; govenment ministers should give a lead in developing the service; all health districts should provide care for STD and HIV infection; all new patients should be seen on the day of presentation or failing that on the next occasion the clinic was open. Other recommendations included: location of all GUM clinics in the general outpatient department of general hospitals; accommodation of the same standard as other outpatient departments; review of the distribution of clinics; review of staffing levels and roles; and coordination of care of HIV infection. Many of these recommendations have already led to action including a lead from government ministers and provision of more funds. Many of the problems and recommendations will apply in other countries.

Since World War 2 there has been a massive increase in the number of patients presenting to venereal disease-sexually transmitted disease (STD)genitourinary medicine (GUM) clinics in England. For example, new cases rose by two thirds from 397,713 to 620,266 between 1977 and $1987 . .^{12}$ In contrast, over the same period staff only increased by $15 \%,{ }^{3}$ and there are no data on change in facilities though anecdotes indicate only modest improvements. In the last decade viral cases of infection increased enormously; between 1977 and 1987

* President, Medical Society for the Study of Venereal Diseases, Member of the Working Group that examined Workloads in Genito Urinary Medicine Clinics on behalf of the Department of Health and Social Security, London, UK. (Based on the Presidential Address to the Medical Society for the Study of Venereal Diseases, April 1989, London).

Address for reprints: Dr R N T Thin, Department of Genitourinary Medicine, St Thomas' Hospital, London SE1 7EH, UK.

Accepted for publication 17 August 1989 cases of genital warts rose from 22,766 to 74,542 and of genital herpes simplex from 7722 to 16,699 . Viral infections are more time consuming and difficult to manage than those caused by bacteria. Patients are becoming increasingly knowledgable and sophisticated with higher expectations and demands for health care. Finally the recent HIV epidemic has resulted in an enormous influx not only of sick patients with complex medical and social problems, but of worried well patients seeking advice counselling and HIV antibody testing. All this has combined to increase work loads of GUM clinics vastly more than the case figures indicate. Though staff in individual clinics were aware of the pressure on their resources it was difficult to obtain an overall view. This prompted the Department of Health and Social Security in 1988 to set up a team to survey GUM Clinics in England with the following terms of reference.

"To examine current and forecast workloads on GUM clinics, taking account of AIDS and other STDs, and to recommend any action which may need to be taken on 
manpower (including nursing manpower), training, resources and accommodation".

The team comprised a recently retired manager as chairman, a GUM consultant, a health adviser in STDs, and a GUM clinic nurse. Towards the end of 1988 the team presented their report. ${ }^{4}$

\section{Method of survey}

The team visited 20 GUM clinics over a three month period. Those selected included full time clinics in large cities and part time clinics in small towns, and included teaching hospitals and non teaching hospitals (district general hospitals). Every health region was visited, clinics were carefully selected as representative of all the clinics in the country, and those visited formed a $10 \%$ sample.

For the administration of health care England is divided into 14 Health Regions which are subdivided into Health Districts. Each district has a population of approximately 150,000 to 300,000 and is served by a general hospital which may for geographical and historical reasons be located on more than one site. Not all districts have a GUM clinic.

The team began each visit by meeting a group of managers and clinic staff for a general discussion which was followed by a tour of the clinic. The members of the team then separated and individually interviewed the corresponding members of the clinic staff. The manager interviewed the secretary and receptionists. These interviews were structured but there was usually time for informal discussion. The team then met the original group for a further general discussion and to expand or clarify details. The visit to the clinic usually took two to three hours. The team then moved on to meet other officers in the district such as a medical officer of health and the district manager, to assess how the GUM clinic and HIV infection services coordinated with general health care provision. The clinics were mainly assessed under the following headings.

Current Workloads-obtained from the returns made to the Department of Health and Social Security on Form SBH 60.

Accommodation - space, suitability in layout, quality of construction and decorative order.

Potential for Expansion-possibility of replacement with new buildings, extension of existing buildings, and internal alterations to improve use of current buildings.

Staffing and Training-number, roles, skills, training. Medical Equipment - number and quality of essential items.

Laboratory and Other Support-types and quality of investigation available.

Appointment Flexibility - how quickly a new patient was seen, and follow up arrangements.

Coordination-of GUM and HIV clinic and other services within hospital, health district and community.

Future plans-for GUM and HIV infection services in districts.

Forecast increase in workloads-as estimated by clinic staff and district officers.

After each visit the team met to discuss their overall impressions and to exchange information. These discussions were detailed and took an hour for each clinic. The different headings were given a numerical rating on a scale of 0 to 10 with 7 being the minimum satisfactory level. These scores were only decided after much thought and debate.

\section{Findings}

\section{CURRENT WORKLOADS}

Workloads had increased in all clinics. All staff considered that the workloads were straining their resources and were concerned about the problems posed by viral infections, (especially wart virus infection), cervical disease and colposcopy.

\section{ACCOMMODATION}

Only eleven clinics were situated in general hospitals and only seven were in general outpatient departments. The quality varied from new purpose built accommodation to appalling adapted premises in basements and yards. Even when quality was good space was limited. Fifteen clinics were regarded as inadequate by the team. Sound attenuation was often lacking, with loss of confidentiality. Poor accommodation resulted in wasted staff time and poor patient flow. For example, four clinics lacked integral counselling accommodation so staff had to take patients to counsellors to avoid them getting lost. The team saw no provision for patients with baby carriages and small children, or for disabled patients.

Staff facilities were poor in many clinics even when they were a long way from staff canteens and rest areas. In cramped conditions food and beverages were seen being prepared on the bench used for infected secretions.

The team gave the lowest numerical score (for clinics in current use, mean $4 \cdot 6$, range 1-8) for accommodation of all the headings so marked. Only five clinics achieved satisfactory scores of 7 or higher.

\section{POTENTIAL FOR EXPANSION}

Fourteen clinics had reasonable possibilities for expansion either by extending existing buildings, taking over adjacent accommodation or by internal alterations to improve existing accommodation. Only two clinics had new buildings under construction and 
in one there were firm plans for a new department though it would be several years before becoming ready.

\section{STAFFING AND TRAINING}

Staffing levels were assessed for doctors, nurses, health advisers in STD, clinical psychologists, receptionists and secretaries. In addition the roles of the doctors, nurses and health advisers were considered.

\section{MEDICAL STAFFING}

The team considered only one clinic had adequate numbers of medical staff, and this was the result of a recent increase. To help to assess staff workload, catchment populations were calculated from health district populations and the proportion of patients coming from the local district. Further calculations were based on 1986 case loads (the latest available in all clinics) and the number of doctor sessions currently being worked. Though the problems with such discordant data are clear, they did allow comparisons to be made between clinics. Mean consultation time was 13.4 minutes (table 1). The number of diagnoses in relation to catchment populations varied from 3.4 to $42 \cdot 1$ while the diagnoses related to doctor sessions varied from 171 to 660 .

Weekly training meetings for doctors were held in all nine teaching hospital clinics and in four general hospital clinics. Staff from all teaching hospital clinics attended other hospital training meetings; staff from four general hospital clinics regularly attended such meetings, staff sometimes attended in five clinics and never attended in two clinics. Consultants encouraged attendance at courses; colposcopy, family planning and management courses had each been attended in 13 clinics, the British Postgraduate Medical Federation Advanced Courses in STDs had been attended in three clinics, and both psychosexual counselling and epidemiology in two clinics. Staff in 18 clinics had attended various HIV infection courses. In one clinic no course had been attended and in one clinic details were unclear.

Staff from all teaching hospital clinics attended national specialist society meetings such as the Medical Society for the Study of Venereal Diseases, and international meetings such as the International

Table 1 Case load in relation to population and doctor sessions

\begin{tabular}{llll}
\hline & $\begin{array}{l}\text { Consultation } \\
\text { times } \\
\text { (minutes) }\end{array}$ & $\begin{array}{l}\text { Diagnoses/ } \\
\text { population } \\
\times 1000\end{array}$ & $\begin{array}{l}\text { Diagnoses/ } \\
\text { doctor } \\
\text { session }\end{array}$ \\
\hline Minimum & $4 \cdot 2$ & $3 \cdot 5$ & 171 \\
Maximum & $27 \cdot 7$ & $42 \cdot 1$ & 660 \\
Mean & 13.4 & 14.3 & 311 \\
\hline
\end{tabular}

Society for STD Research and the International Union against Venereal Diseases and Treponematoses. Support for these meetings was poor among general hospital clinics and centred on recently appointed consultants.

\section{NURSING STAFFING}

The team considered only two clinics had adequate numbers of nurses. Seventeen clinics had filled their establishments but still had too few nurses. Recruitment was more difficult in London than elsewhere. Nurses' job content varied as shown in table 2. Though venepuncture was performed by nurses in all clinics, they undertook microscopy in only 10 clinics. Nurses kept records in 12 clinics; these varied from recording all cytology smear requests to completing statistical returns such as that for case load (SBH 60, now KC 60).

Responsibilities of nurses varied and appeared more related to local custom and practice than to experience, training and skills.

Training was mainly within the clinics. The two formal training courses were held in low regard. The English National Board (ENB) 275 Course of 26 to 30 weeks was considered too long by nurses, doctors and managers in most clinics and in only three clinics had nurses completed it. The ENB 932 course of five days was thought too short but seven clinics had staff who had attended it. Nurses had attended other courses such as those on HIV infection, counselling and management.

\section{HEALTH ADVISERS IN STD}

Nineteen clinics had health advisers, the remaining clinic having no established post. Staff in 11 clinics considered that staffing was inadequate and this was agreed by the team. Staff in 18 clinics reported an increase in work related to other STDs in addition to HIV infection. In all clinics the health advisers' role included contact tracing, counselling and health education. In all 19 clinics they undertook contact tracing for syphilis and gonorrhoea, and in 15 clinics they traced for other infections including warts and pelvic inflammatory disease. In 18 clinics contact

Table 2 Number of clinics with nurses extended role

\begin{tabular}{lll}
\hline Activity & $\begin{array}{l}\text { No of } \\
\text { clinics }\end{array}$ & $\begin{array}{l}\text { \% of } \\
\text { clinics }\end{array}$ \\
\hline Venepuncture & 20 & 100 \\
Dispensing drugs & 18 & 90 \\
Follow up investigations & 16 & 80 \\
Podophyllin application & 15 & 75 \\
Record keeping & 12 & 60 \\
Microscopy & 10 & 50 \\
Taking cervical cytology smears & 10 & 50 \\
Cryotherapy & 7 & 35 \\
\hline
\end{tabular}


Workloads in genitourinary medicine clinics in England tracing included visits in the community to secure the attendance of contacts.

All clinics provided pre and post test counselling for HIV antibody testing. Counselling was also available for patients with other conditions. Eleven clinics had access to a clinical psychologist or psychiatrist.

All clinics with health advisers provided health education for patients in the clinics. Thirteen clinics provided health education outside the clinic.

Currently all training for health advisers is provided informally though the Society of Health Advisers in STD has guidelines and senior members provide assistance. The Handbook on Contact Tracing in STDs 5 was published in 1980 and needs to be updated. Currently no formal course in health advising in STD is available though there was interest among all health advisers in such a course.

\section{MEDICAL EQUIPMENT}

Medical equipment is summarised in table 3. All clinics had an adequate number of modern good quality microscopes but only nine had a colposcope. The number with incubators depended on culture methods and transport media. In two clinics there was confusion between the refrigerator used for specimens and media, and that used for food and beverages.

Training equipment was much less satisfactory as shown in table 4. Seven clinics had no journals and four had no books. Recommended safe procedures, for example the disposal of sharps, were not followed in some clinics.

\section{DIAGNOSTIC SUPPORT SER VICES}

On the whole diagnostic supporting services were satisfactory as shown in table 5 . Low scores were because of slow return of reports and in the case of chlamydia reflected limitations on the number of samples accepted.

\section{APPOINTMENT FLEXIBILITY}

All clinics saw urgent cases on the day of presentation but in some clinics less urgent cases had to wait; the mean delay was 7 days but in three clinics it was 21 days. Many clinics saw follow up patients by appointment. The number of follow up visits per new diag-

Table 3 Number of clinics adequately supplied with medical equipment

\begin{tabular}{lll}
\hline Equipment & $\begin{array}{l}\text { No of } \\
\text { clinics }\end{array}$ & $\begin{array}{l}\% \text { of } \\
\text { clinics }\end{array}$ \\
\hline Microscopes & 20 & 100 \\
Cryotherapy & 20 & 100 \\
Incubators & 17 & 85 \\
Refrigerator & 17 & 85 \\
Electrocautery & 13 & 65 \\
Colposcope & 9 & 45 \\
\hline
\end{tabular}

Table 4 Teaching and training equipment

\begin{tabular}{lll}
\hline Aid & $\begin{array}{l}\text { No of } \\
\text { clinics }\end{array}$ & $\begin{array}{l}\text { \% of } \\
\text { clinics }\end{array}$ \\
\hline Microscope arm & 8 & 40 \\
Satisfactory journals & 7 & 35 \\
Satisfactory books & 5 & 25 \\
No journals & 7 & 35 \\
No books & 4 & 20 \\
\hline
\end{tabular}

nosis ranged from 2.0 to 3.2 with a mean of 2.6 visits. Ten clinics restricted opening times from 9 am to $5 \mathrm{pm}$.

\section{COORDINATION}

Coordination only involved the GUM clinic and its staff to a limited extent and concerned HIV infection more than STDs. The team found coordination to be very poor in many districts and gave a mean score of 4.8 (range 1-8), the second lowest, against a satisfactory score of 7 . Only four districts had satisfactory scores.

\section{FUTURE PLANS}

Only one health region appeared to have an overall plan for GUM and HIV infection services. Five districts were actively planning for the future, four districts had some plans, six districts had very few plans and five were barely aware of any need to plan for the future of GUM and HIV infection services. Though additional funding had recently been made available for HIV infection services, some clinics were unaware of this.

\section{FORECASTS OF WORKLOAD}

Accurate forecasting of workloads in GUM and HIV infection is difficult. Two districts had forecasts based on statistics; otherwise forecasts were based on opinions and the team were careful to obtain such estimates from as many people as possible. When a district had had few cases of HIV infection only very small increases were forecast. Sixteen districts forecast increases in workloads on GUM clinics.

Table 5 Number of clinics with satisfactory diagnostic support services

\begin{tabular}{lll}
\hline Discipline & $\begin{array}{l}\text { No of } \\
\text { clinics }\end{array}$ & $\begin{array}{l}\% \text { of } \\
\text { clinics }\end{array}$ \\
\hline Conventional radiodiagnosis & 20 & 100 \\
Ultrasound and computerised & 20 & 100 \\
tomographic scanning & 20 & 100 \\
Cytology & 18 & 90 \\
Microbiology & 17 & 85 \\
Virology & 14 & 70 \\
Chlamydia identification & & \\
\hline
\end{tabular}




\section{Conclusion}

The team concluded that the GUM service was ill equipped to meet the demands for its services. The report went on to make 36 recommendations.

\section{Recommendations}

There were five priority recommendations which were: designating the GUM service as a priority; providing more resources; a lead from government ministers in developing the service; and that all health districts should have some form of provision of care for GUM and HIV infection. In addition, all patients with a new problem suggesting the possibility of STD should be seen on the day of presentation or failing that on the next occasion the clinic was open.

Other recommendations included; GUM clinics should be situated in the general outpatient department of a general hospital, the premises should conform with the general standard for outpatient departments and have adequate sound attenuation, and clinics should be clearly signposted from hospital entrances. Distribution of clinics should be reviewed. Staffing levels and the roles of different groups of staff should be examined. All clinics should have access to clinical psychologists or psychiatrists. In accordance with the Public Health (Venereal Diseases) Regulations of 1916 which remain in force, some clinic sessions should be held after $5 \mathrm{pm}$. Activities in relation to HIV infection should be carefully coordinated.

\section{Comment}

The conclusion that the GUM clinic service was illequipped to meet the demands placed upon it has been well known to clinic staff for many years. Since the team reported the total cases in clinics have shown a fall in the year 1 April 1987 to 31 March $1988,{ }^{2}$ though it remains to be seen if this is transient or longer lasting. Clinics so lack resources that the findings of the report will remain relevant.

The feature of clinics most strongly condemned was accommodation. It was so bad that it was suggested in the report that attendance could be regarded as punitive, which is not a desirable feature for a service with the prime aim of controlling infection by attracting patients. In the 1990s consideration must be given to the needs of the disabled and parents with small children. The Public Health (Venereal Diseases) Regulations of 1916 recommended that clinics are situated in general hospitals; more managers need to be made aware of this principle. Though there was a reasonable possibility of expanding 14 clinics, only eight were seriously planning for the future.
Findings in relation to staffing revealed serious problems. The roles of different groups and their interrelationships need examination, especially those of nurses and doctors. Only when these have been clarified can rational consideration be given to the ratio of staff to case load; at present there are no data on this basic relationship. Clearly relevant training for staff must be provided; the lead for such training should come from the Department of Health.

Medical equipment and diagnostic support, crucial for a good clinical service, were among the best features of the clinics and these standards must be maintained. More clinics need colposcopes and trained colposcopists. It is essential that new patients are seen promptly. Delay discourages attendance, leads to spread of infection and to complications including pelvic inflammatory disease which increases suffering of patient and family and the load on health and community services. The difficulties endured by a patient attending a series of overstretched clinics without being seen have been graphically described. ${ }^{6}$ Data for diagnoses in relation to population and doctor sessions are crude but allow simple comparisons. When the diagnoses in relation to population and doctor sessions were examined, half the clinics below the mean for diagnoses in relation to population were above the mean for diagnoses per doctor session. This suggests that there were too few sessions for the case load in the population, but when the clinic was open the doctors were working hard. This suggestion is supported by the mean consultation time of 13.4 minutes which contrasts with recommendations by the Royal College of Physicians to the Department of Health and Social Security of a mean of 20 minutes for all visits; this included new patients and colposcopic examination.?

Many of the recommendations have already led to action. Government ministers have stated unequivocally that GUM services should be substantially upgraded for they are crucial in controlling the spread of HIV infection, and have made additional funds available. ${ }^{8}$ These funds are for various purposes related to HIV infection and clinic staff will have to ensure adequate funding becomes available to them. The Department of Health organised a conference for GUM clinic staff which was opened by the Minister of Health, thus showing that the Government was giving a lead in developing the service. Various initiatives are under way to implement other recommendations, such as a review of the guidelines for building standards for GUM clinics. Ministers have made it clear that they consider that GUM has a vital role in the reorganised health service as outlined in the Government White Paper.'

Many of the deficiencies and recommendations in this report will apply to venereal diseases-sexually 
transmitted diseases-genitourinary medicine and HIV infection services in other countries, as shown for example in Australia, ${ }^{10}$ and the report merits wide circulation.

\section{References}

1 Catterall RD. The emergence of a speciality. Sex Transm Dis 1983; 10:85-92.

2 New cases seen in NHS genitourinary medicine clinics in England in 1977-1987. London: Department of Health 1989 (Statistical Bulletin).

3 Adler MW. A unique opportunity to upgrade genitourinary medicine. Br Med J 1989;298:1201-2.
4 Report of the working group to examine workloads in genitourinary medicine clinics. London: Department of Health, 1988.

5 Hunter I, Jacobs J, Kinnell H, Satin A. Handbook on contact tracing in sexually transmitted diseases. Health Education Council, 1980: London.

6 Anonymous. Personal view. Br Med J 1986;292:1735.

7 Committee on Genitourinary Medicine. Future manpower requirements and maintenance of standards of clinical care in departments of genitourinary medicine. London: Royal College of Physicians, 1986.

8 Mellor D. HIV and AIDS resources 1989. London: Department of Health.

9 Secretaries of State for Health, Wales, Northern Ireland and Scotland. Working for patients. 1989; London: Her Majesty's Stationery Office.

10 Denham I, Plummer D. Future of the Melbourne STD service. Venereology 1989;2:31. 